\title{
Double Blind Comparative Trial of Abana and Methyldopa for Monotherapy of Hypertension in Indian Patients
}

\author{
Vaishali N. Dadkar, M.D., Rajlata R. Tahiliani, M.D., * \\ Veena S. Jaguste, M.D., V. B. Damle, M.D.,* \\ and H. L. Dhar, Ph.D.
}

\section{Summary}

Abana is a herbomineral medicinal preparation with a property of down-regulation of beta-adrenergic receptors. A double-blind, parallel group study was conducted in 43 Indian men and women suffering from hypertension to evaluate the antihypertensive effect of Abana and compare it with that of methyldopa (M-DOPA). Twenty-one patients received $800 \mathrm{mg}$ tds of Abana and 22 patients received $250 \mathrm{mg}$ tds of $\mathrm{M}$ DOPA for 4 weeks. Blood pressure and pulse rate were recorded at weekly intervals. Relevant clinical and biochemical investigations were carried out before and after treatment.

In patients treated with Abana, there was a significant fall both in systolic B.P. (from $167 \pm 3.73$ to $145 \pm 6.11 \mathrm{mmHg}$ ) and in diastolic B.P. (from $110 \pm 1.86$ to $91 \pm 3.04 \mathrm{mmHg}$ ) at the end of 4 weeks. Similarly in patients treated with M-DOPA, systolic blood pressure was significantly reduced from $165 \pm 4.92$ to $146 \pm 4.9 \mathrm{mmHg}$ and diastolic blood pressure was reduced from $106 \pm 2.74$ to $96 \pm 2.67 \mathrm{mmHg}$ after 4 weeks. The onset of antihypertensive effect was earlier and there was a higher percentage of responders $(80 \%)$ in the Abana-treated group. None of the patients had clinically or biochemically significant side-effects. The results of this study suggest that therapy with Abana proved highly effective in hypertensive patients.

\section{Additional Indexing Words:}

Abana Methyldopa (M-DOPA) Hypertension Monotherapy

TN recent years, there has been an alarming increasc in cardiovascular diseases in man, so the search for a relatively safe and clinically uscful drug is the need of the hour. Abana is a compound preparation of medicinal plants and mineral complexes." It contains a number of ingredients de-

From the Departments of Pharmacology and Medicine,* L.T.M. Medical College, Sion, Bombay 400 022, Maharashtra, India.

Part of this work was presented at the Xth International Congress of Pharmacology held in Sydney, Australia, in August, 1987.

Received for publication January 6, 1989.

Accepted August 1, 1989. 
Table I. Composition of Abana Capsule (400 mg)

$\begin{array}{lr}\text { Terminalia arjuna (Arjun) } & 30 \mathrm{mg} \\ \text { Withania somnifera (Ashwagandha) } & 20 \mathrm{mg} \\ \text { Tinospora cordifolia (Giloe) } & 10 \mathrm{mg} \\ \text { Boerhaavia diffusa (Punarnava) } & 10 \mathrm{mg} \\ \text { Nardostachys jatamansi (Jatamansi) } & 10 \mathrm{mg} \\ \text { These ingredients were processed appropriately as per Ayurvedic } \\ \text { principles by incorporating some other herbomineral ingredients. }\end{array}$

scribed in ancient Ayurvedic literature, having action on the cardiovascular system. Some of the important ingredients are listed in Table I. Experimental and clinical studies have shown that this preparation possesses the property of down-regulation of beta-adrenergic receptors. ${ }^{2), 3)}$ It has been found to be safe in patients with bronchial asthma (no aggravation of respiratory symptoms) and in diabetic patients (no aggravation of insulin mediated hypoglycemia). ${ }^{4 i}$ A few of the earlier studies have indicated that it has no effect in normotensives but reduces blood pressure in patients with mild or moderate hypertension. ${ }^{51}$ These observations prompted us to undertake a double-blind, parallel study to evaluate the effects of Abana in all grades of hypertension and to compare these effects with those of M-DOPA, one of the most widely used antihypertensive agents.

\section{Materials and Methods}

The patients included in the trial were those reporting to the Medical Outpatient Department. They were thoroughly examined for clinical signs and symptoms. Their blood pressure and pulse rate were recorded. $\mathrm{Pa}$ tients with all grades of hypertension, that was either newly detected or resistant to previous drug therapy were informed about the trial and were enrolled after signing a consent form. A chest film, EGG, fundoscopy and serum sodium, potassium, creatinine, cholesterol, SGOT, glucose, hemoglobin, total WBG count and urinc analysis werc performed.

Patients with satisfactory results for these studies were considered for drug therapy. Patients with recent history of myocardial ischemia, congestive cardiac failure, left ventricular failure, renal failure or cerebrovascular accidents were excluded from the study.

Forty-three patients (aged 35-70 years) were randomized to receive Abana or M-DOPA in the double-blind, parallel group trial. In the beginning, identical placebos were given for 2-3 weeks to wash out previous antihypertensive drugs, if any. Then the patients received either 2,400 $\mathrm{mg}$ of 
Abana or $750 \mathrm{mg}$ of M-DOPA orally daily in 3 equally divided doses for 4 weeks. Selection of doses was on the basis of our clinical practice and doses were adjusted whenever necessary.

Blood pressure and pulse rate were recorded in the supine position by the same doctor at the same time of the day at weekly intervals, using the same sphygmomanometer. The mean of three readings was noted.

At the end of 4 weeks of drug therapy, chest $x$ ray, EGG and laboratory investigations were repeated, drug therapy was tapered off and patients' numbers were decoded. Results are expressed as mean \pm SEM.

A patient was categorized as a 'responder' if his or her diastolic blood pressure at the end of the study period was less than $95 \mathrm{mmHg}$ (accepted by WHO) or if there was a fall of $20 \mathrm{mmHg}$ or more in diastolic blood pressure as compared to the initial value.

For comparison of the antihypertensive activity of these 2 agents, reduction in diastolic B.P. from 0 to 4 weeks was calculated as the area under the curve (AUC) using the trapezoidal rule. For statistical analysis, paired t-test and one-way analysis of variance followed by Duncan's multiple range test, were employed.

\section{RESULTS}

All patients completed 4 weeks of drug therapy. On decoding it was found that 21 patients received Abana and 22 patients received M-DOPA. Mean age of patients in the Abana trcated group was 54 years (range, 38 to 67 years) and the mean age of patients receiving M-DOPA was 57 years (range, 35 to 70 years). The age and sex distributions in both groups were similar.

In patients treated with Abana, initial systolic blood pressure (week 0) was $167 \pm 3.73 \mathrm{mmHg}$ and diastolic blood pressure was $110 \pm 1.86 \mathrm{mmHg}$. After 4 weeks of therapy, the respective pressures were reduced to $145 \pm 6.11$ and $91 \pm 3.04 \mathrm{mmHg}$. A significant fall in both systolic and diastolic B.P. was evident within 1 week; there was a further fall for up to 3 weeks and then it was maintained. Heart rate at week 0 was $92 \pm 3$ per minute and at the end of 4 weeks of therapy it was $84 \pm 4$ per minute. Though there was an apparent reduction in the heart rate, it did not reach statistical significance (Fig. 1). In patients treated with M-DOPA over a period of 4 weeks the systolic B.P. was brought down from $165 \pm 4.92$ (week 0) to $146 \pm 4.9 \mathrm{mmHg}$ and diastolic blood pressure was brought down from $106 \pm 2.74$ (week 0 ) to $96 \pm 2.67 \mathrm{mmHg}$. In this group, significant falls in both systolic and diastolic B.P. were observed only after 2 weeks and it was maintained thereafter. 
Heart rate was not significantly affected by treatment with this agent (week $0,85 \pm 2$ and at the end of 4 weeks $87 \pm 2$ ) (Fig. 2).

The extent of the fall in diastolic B.P. in individual subjects treated with these agents is shown in Fig. 3. It was evident in 14 patients treated with Abana that diastolic B.P. was brought down to $95 \mathrm{mmHg}$ or less, while in 3 paticnts the fall in diastolic B.P. was more than $20 \mathrm{mmHg}$ in the 4 week period. Thus 17 of 21 (nearly $80 \%$ ) showed a satisfactory response to therapy. Of 22 patients treated with M-DOPA, diastolic blood pressure was brought down
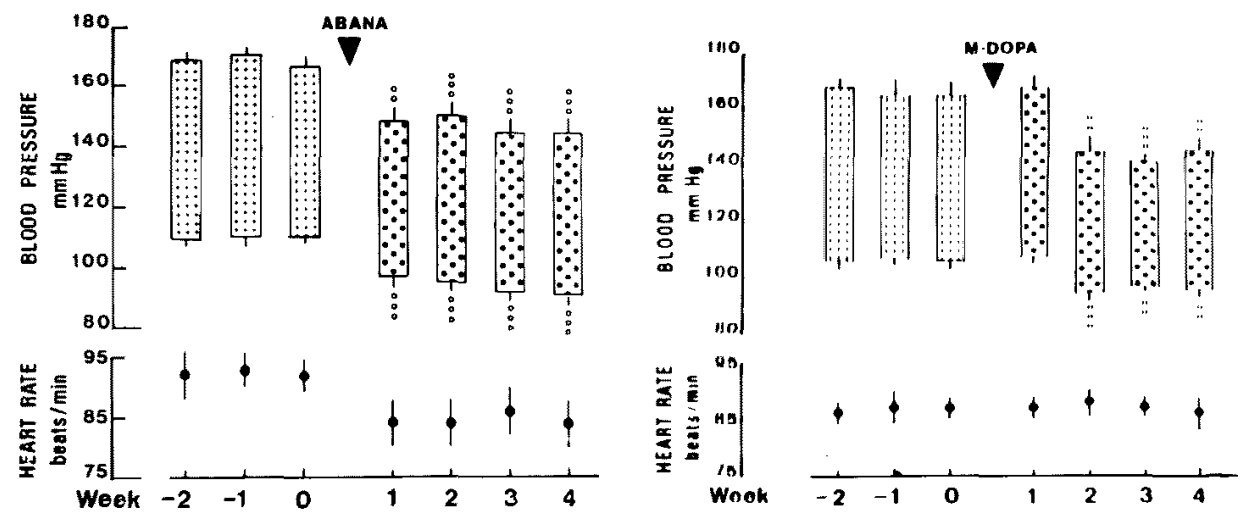

Fig. 1. Effect of Abana (800 $\mathrm{mg}$ tds) on blood pressure and heart rate in hypertensive patients $(n=21)$. $00 \mathrm{p}<0.005,000 \mathrm{p}<0.001$.

Fig. 2. Effect of M-DOPA (250 mg tds) on blood pressure and heart rate in hypertensive patients $(n=22) . \quad:: p<0.005,::: p<0.001$.

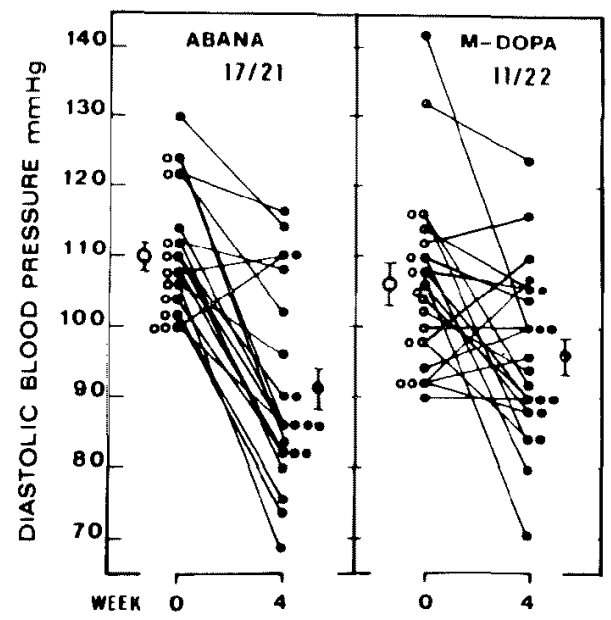

Fig. 3. Diastolic blood pressure changes following treatment with Abana and M-DOPA in individual hypertensive subjects. Abana $(n=21)$ and $M-$ DOPA $(n=22)$. 
to $95 \mathrm{mmHg}$ or less in 10 patients and in 1 patient the fall in diastolic blood pressure was more than $20 \mathrm{mmHg}$ in the 4 week period. Thus 11 of the 22 paticnts, i.e. $50 \%$ showed satisfactory response as judged by the above mentioned criteria. Though the number of responders to Abana therapy appeared to be higher as compared to those receiving M-DOPA, the difference in response rates was not statistically significant ( $\mathrm{Chi}^{2}$ value 3.27). However, the fall in diastolic B.P. expressed as AUC (0-4 weeks) was significantly

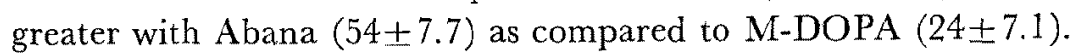

Since the fall in blood pressure on treatment with Abana was earlier in onset and greater in magnitude as compared to M-DOPA, the effect of withdrawal of Abana after 4 weeks treatment was studied in a few subjects. Placebo was substituted during this period. Here again, it was observed that there was no rebound hypertension, though the extent of the fall in diastolic B.P. was less (Fig. 4).

Regarding side-effects, none of the patients complained of giddiness and there was no evidence of skin rash. All biochemical and clinical investigations remained within physiological limits at the end of therapy (Table II).

\section{Discussion}

In recent times, there has been a renewed interest in herbal remedies and studies have been carried out to establish the clinical efficacy of compound preparations. ${ }^{6)}$ Abana, as mentioned earlier, is a herbomineral compound preparation." Its property of down-regulation of beta-receptors can protect the heart against sympathetic outbursts. ${ }^{3), 8}$ Some of the earlier studies have indicated its efficacy and safety in angina pectoris, sinus tachy-

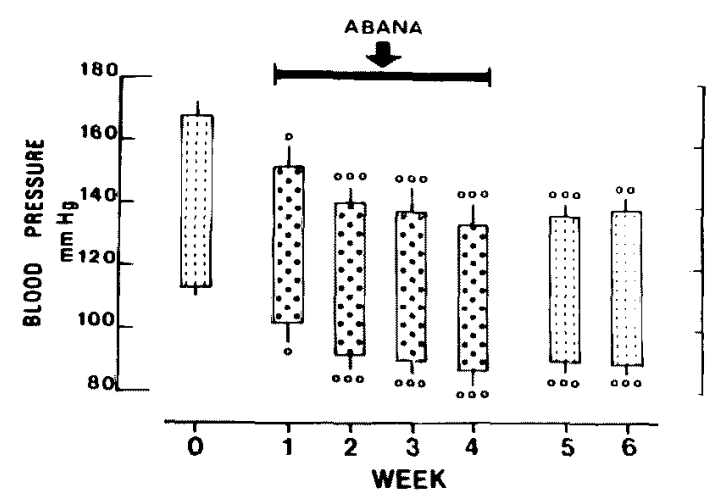

Fig. 4. Effect of discontinuation of Abana ( $800 \mathrm{mg}$ tds) after 4 weeks of therapy $(n=10)$. $00 \mathrm{p}<0.005,000 \mathrm{p}<0.001$. 
Table II. Effect of Abana and M-DOPA on Biochemical Parameters, Urinary Electrolytes and Selected Hematological Parameters

\begin{tabular}{l|cc|cc}
\hline \multirow{2}{*}{ Parameter } & \multicolumn{2}{|c|}{ Abana } & \multicolumn{2}{c}{ M-DOPA } \\
\cline { 2 - 4 } & Initial & $\begin{array}{c}\text { After } \\
\text { weeks }\end{array}$ & Initial & $\begin{array}{c}\text { After } \\
\text { weeks }\end{array}$ \\
\hline Blood sugar. (mg\%) & $112 \pm 4.05$ & $111 \pm 4.93$ & $107 \pm 3.01$ & $118 \pm 5.43$ \\
SGOT (units) & $12 \pm 1.35$ & $14 \pm 1.52$ & $16 \pm 1.54$ & $14 \pm 1.11$ \\
Serum Creatinine (mg\%) & $1.30 \pm 0.09$ & $1.50 \pm 0.08$ & $1.40 \pm 0.07$ & $1.30 \pm 0.10$ \\
Serum Cholesterol (mg\%) & $184 \pm 7.09$ & $192 \pm 9.24$ & $207 \pm 11.00$ & $201 \pm 10.00$ \\
Serum Alk. Phosphatase & $10.00 \pm 0.92$ & $9.30 \pm 0.79$ & $8.80 \pm 0.90$ & $8.90 \pm 0.68$ \\
$\quad$ K units) & $90 \pm 11.90$ & $112 \pm 9.76$ & $101 \pm 6.51$ & $95 \pm 8.83$ \\
Urine Sodium (meg/lit) & $33 \pm 5.32$ & $42 \pm 4.66$ & $30 \pm 3.00$ & $21 \pm 2.86$ \\
Urine Potassium (meg/lit) & $11.70 \pm 0.34$ & $12.40 \pm 0.33$ & $13.00 \pm 0.35$ & $13.00 \pm 0.32$ \\
Hemoglobin (g\%) & $6995 \pm 473.00$ & $7424 \pm 451.00$ & $7518 \pm 385.00$ & $6791 \pm 336.00$ \\
WBC (cells/HPF) & & &
\end{tabular}

cardia and ischemic heart diseases.7),9) This trial report highlights the antihypertensive effect of Abana, in comparison with an established and widely used older drug, M-DOPA. Treatment with Abana produced an early, sustained and significant fall, both in systolic and diastolic blood pressure, whereas in patients treated with M-DOPA, fall in blood pressure was seen only at the end of 2 weeks. It was observed that out of 21 patients, only 4 did not respond to therapy with Abana. Thus, the response rate was $80 \%$ as against $50 \%$ in M-DOPA treated patients. In addition, the fall in diastolic blood pressure calculated as area under the curve (AUG 0-4 weeks) was significantly greater in Abana treated patients and there was no evidence of rebound hypertension on its withdrawal. It is well known that with advancing age, responses of beta-receptors decrease. ${ }^{10)}$ This may cause disturbing features like tachycardia and angina. Abana, by down-regulation of beta-receptors, might be bringing about beneficial effects in a more physiological way.

In conclusion, the results of the present study using Abana in a total dose of 2,400 mg per day and M-DOPA $750 \mathrm{mg} /$ day indicated that the antihypertensive effect of the former agent was better than that of M-DOPA. The patient compliance was good for both agents and there were no appreciable side-effects. Abana proved to be an effective and safe drug for the therapy of hypertension in our patients.

\section{REFERENCES}

1. Singh N, Singh SP, Pant KK, Dixit KS, Kohli RP: Some cardiovascular effects of Abana, an Ayurvedic herbal drug combination. Probe 25: 17, 1985 
2. Gulati OD, Pasnan JS, Hemavati KG: Effect of Abana, an Ayurvedic preparation, on rabbit atrium and intestine. J Ethnopharmacology 24: 287, 1988

3. Thatte MS, Doshi BS, Kulkarni RD: Effect of Abana on beta receptors. Indian Drugs 23: 598,1986

4. Trivedi BB, Shukla SL: The management of ischaemic heart disease and hypertension with Abana. Probe 25: 60, 1985

5. Salkar RG, Salkar HR, Deshmukh PY: Role of Abana in hypertension. The Antiseptic 84: 719,1987

6. Attisso MA: Phytopharmacology and Phytotherapy in Traditional Medicine and Health Care Coverage, ed by Bannerman RH, Bunton J, Chich CV, WHO, Geneva, p 195, 1983

7. Dubey GP, Agrawal A, Udupa KN: Prevention and management of coronary heart disease by an indigenous compound-Abana. Alternative Medicinc 3: 241, 1986

8. Shaligram SV, Panicker R: Effect of chronic treatment with Abana on the responsiveness of the guinea pig bronchial musculature to 150 isoprenaline. Journal of JJ Group of Hospitals and GM College 30: 37, 1985

9. Growda NG, Ghinniah D: The management of angina pectoris, hypertension and tachycardia with Abana. Probe 25: 69, 1985

10. Pan HYM, Hoffman BB, Pershe RA, Blaschke TF: Decline in beta adrenergic receptor mediated vascular relaxation with aging in man. J Pharmacol Exp Ther 239: 802, 1986 